\title{
Neutronics Assessment of Accident-Tolerant Fuel in Advanced Power Reactor 1400 (APR1400)
}

\author{
D. Hartanto*, A. Alshamsi, A. Alsuwaidi, A. Bilkhair, H.A. Hukal and M. Zubair \\ Department of Mechanical \& Nuclear Engineering, University of Sharjah, P.O. Box 27272, Sharjah, United Arab Emirates
}

\section{ARTICLE INFO}

Article history:

Received 9 July 2020

Received in revised form 25 August 2020

Accepted 26 August 2020

Keywords:

APR1400

Neutronics assessment

Accident tolerant fuel

Serpent

ENDF/B-VII.1

\begin{abstract}
A B S T R A C T
Safety and reliability are the most desirable conditions that each nuclear power plant should improve. Since the Fukushima Daiichi accident, Accident-Tolerant Fuel (ATF) has been extensively researched to improve the performance of the nuclear fuel system. This paper presents the investigation of the ATF system from a neutronics perspective, which positively reflects on the performance of the APR1400 nuclear power plant. Several advanced fuel candidates such as $\mathrm{UC}, \mathrm{U}_{3} \mathrm{Si}_{2}$, and $\mathrm{UN}$, which have better thermophysical properties than current $\mathrm{UO}_{2}$ nuclear fuel, have been considered. Meanwhile, advanced cladding candidates such as $\mathrm{FeCrAl}$, $\mathrm{Zr}$-alloy with coating, and $\mathrm{SiC}$ which can reduce or even eliminate the oxidation rate of current $\mathrm{Zr}$-alloy cladding have been adopted in this study. The Monte Carlo Serpent code, in conjunction with ENDF/B-VII.1 nuclear data library, has been used to calculate and evaluate the important neutronics parameters at the assembly level such as the fuel residence time, discharge burnup, kinetics parameters, pin power distribution, temperature reactivity feedbacks, and fissile evolution. The advanced fuels show better neutronics performance than the current $\mathrm{UO}_{2}$ fuel. In addition, $\mathrm{SiC}$ provides optimum neutronic performance as cladding.
\end{abstract}

\section{INTRODUCTION}

The devastation left by the Fukushima Daiichi nuclear accident questions the performance of the nuclear fuel system in the Light Water Reactors (LWRs) during accident conditions. The severe damage of the current nuclear fuel system which consists of $\mathrm{UO}_{2}$ fuel and $\mathrm{Zr}$-alloy cladding caused the hydrogen explosion and the release of radioactive materials to the environment. Consequently, this accident has demoted public acceptance towards nuclear energy and slowed down the construction rate of nuclear power plants. As an outcome to enhance fuel safety and reliability during normal and accident conditions, the AccidentTolerant Fuel (ATF) concept has been investigated extensively such in PWRs (pressurized water reactors) [1-4] PHWRs (pressurized heavy water reactors) [5], VVER (Russian's PWR) [6]. ATF consists of a fuel and cladding system that can

${ }^{*}$ Corresponding author.

E-mail address: dhartanto@ sharjah.ac.ae

DOI: https://doi.org/10.17146/aij.2020.1073 tolerate severe accidents occurring in the reactor core for a period longer than the one of the current $\mathrm{UO}_{2} / \mathrm{Zr}$-alloy fuel system. Moreover, the ATF should enhance the thermal, mechanical, chemical properties, and the economics of the current fuel system $[7,8]$.

Choosing the suitable enhanced fuel and cladding to replace the current fuel system in the LWRs is challenging. It requires comprehensive feasibility studies to examine the changes in the fuel system's performance under several conditions starting from the normal operating conditions in the reactor core to the most severe incidents that could occur. Moreover, any new concept regarding the accident tolerance fuel concept should be evaluated in constraints of safety, current design, and operational desires and requirements to assess the regulatory safety commitment with operational constraints [9].

The objective of this paper is to investigate and evaluate the performance of the ATF system from a neutronics perspective in the APR1400 (Advanced Power Reactor 1400) nuclear power 
plant. The reactor was designed by Korea Electric Power Corporation (KEPCO) and produces about 1455 MWe power. Furthermore, it is considered as one of the most advanced pressurized water reactor designs that meets the highest international standards in performance and safety [10].

In this study, combinations of several advanced fuels and claddings were considered for the ATF system, and Serpent Monte Carlo code [11] was used to simulate the neutronics properties. The calculation was performed in a two-dimensional fuel assembly lattice. Several important neutronics characteristics such as discharged burnup, fuel residence time, fuel and moderator temperature reactivity feedbacks, pin power distribution, fissile isotopes evolution, and kinetics parameters were evaluated and compared among current nuclear fuel system and the ATF systems. In addition, the radial temperature distribution of the combined advanced fuel and cladding systems was calculated for a single fuel rod at the average condition as the input data for the Monte Carlo code Serpent.

The paper is organized as follows. The considered advanced fuels and claddings are discussed in section 2. Section 3 describes the APR1400 fuel assembly, while section 4 evaluates and discusses the results. The conclusion and recommendation for future works are given in section 5 .

\section{ADV ANCED FUELS AND CLADDINGS}

\section{Advanced fuels for ATF}

Recently, many fuels have been studied and proposed to replace the current $\mathrm{UO}_{2}$ fuel in light water reactors. However, in this study, three different advanced fuels were considered. The preferred fuels for ATF system were $\mathrm{U}_{3} \mathrm{Si}_{2}$ [12-15], UN $+\mathrm{U}_{3} \mathrm{Si}_{2}$ [16-18], and UC [19]. The thermophysical properties of the three advanced fuels and $\mathrm{UO}_{2}$ fuels for the APR1400 fuel assembly are summarized and compared in Table 1 including fuel density $\rho$, heavy metal density $\rho_{H M}$, average fuel temperature $\bar{T}_{\text {fuel }}$, thermal conductivity $k$, specific heat $C_{p}$, and fuel melting temperature $T_{\text {melt }}$. The advanced fuels are characterized by having higher densities and, consequently, higher heavy mass contents, and higher thermal conductivities compared to the $\mathrm{UO}_{2}$ fuel.

$\mathrm{U}_{3} \mathrm{Si}_{2}$, a proven nuclear fuel, has been widely used in research reactors [20]. UC has also been investigated as nuclear fuel for very high- temperature reactors [21]. Similarly, UN has been proposed as a potential nuclear fuel for lead-cooled fast reactors [22]. In this study, UN was mixed with $\mathrm{U}_{3} \mathrm{Si}_{2}$ with a volume fraction of $70 \%$ and $30 \%$ to provide a protective barrier by waterproofing UN and to provide oxidation tolerance [15].

Table 1. Thermal properties of the advanced fuels when combined with $\mathrm{Zr}$ cladding.

\begin{tabular}{lllll}
\hline Properties & $\mathbf{U O}_{2}$ & $\mathbf{U}_{3} \mathbf{S i}_{2}$ & $\mathbf{U N}+\mathbf{U}_{3} \mathbf{S i}_{2}$ & $\mathbf{U C}$ \\
\hline $\begin{array}{l}\rho \text { at } 95 \% \text { T.D. } \\
\left(\mathrm{g} / \mathrm{cm}^{3}\right)\end{array}$ & 10.40 & 11.59 & 13.16 & 12.92 \\
$\rho_{H M}\left(\mathrm{~g} / \mathrm{cm}^{3}\right)$ & 9.13 & 10.74 & 12.15 & 12.30 \\
$\bar{T}_{\text {fuel }}(\mathrm{K})$ & 929.36 & 693.98 & 683.37 & 685.49 \\
$k$ at $T_{f_{\text {avg }}}(\mathrm{W} / \mathrm{m} . \mathrm{K})$ & 3.29 & 16.78 & 20.31 & 21.22 \\
$C_{p}$ at $T_{f_{\text {avg }}}(\mathrm{J} / \mathrm{kg} \cdot \mathrm{K})$ & 82.75 & 271.17 & 273.93 & 237.08 \\
$T_{\text {melt }}(\mathrm{K})$ & 3120 & 1938 & $3123(\mathrm{UN})$ & 2623 \\
\hline
\end{tabular}

\section{Advanced claddings for ATF}

The failure of $\mathrm{Zr}$-alloy during the Fukushima Daiichi nuclear disaster is the main reason behind the introduction of the ATF system. In this study, 3 types of advanced claddings were investigated including $\mathrm{FeCrAl}, \mathrm{Zr}$-alloy with $\mathrm{Nb}_{2} \mathrm{AlC}$ coating, and $\mathrm{SiC}$. The thermophysical properties of the advanced cladding for the fuel assembly of APR1400 are summarized and compared in Table 2 including the average cladding temperature $\bar{T}_{\text {clad }}$, cladding thermal conductivity $k$, specific heat $C_{p}$, and cladding melting temperature $T_{\text {melt }}$.

Table 2. Thermal properties of the advanced claddings when combined with $\mathrm{UO}_{2}$ fuel.

\begin{tabular}{cccc}
\hline Properties & FeCrAl & $\begin{array}{c}\mathbf{Z r}+\mathbf{N b}_{2} \mathbf{A l C} \\
\text { coating }\end{array}$ & SiC \\
\hline $\bar{T}_{\text {clad }}(\mathrm{K})$ & 608.35 & 606.93 & 597.93 \\
$k$ at $\bar{T}_{\text {clad }}$ & 15.81 & 18.04 & 126.43 \\
$\begin{array}{c}(\mathrm{W} / \mathrm{m} . \mathrm{K}) \\
C_{p} \text { at } \bar{T}_{\text {clad }}\end{array}$ & 669.70 & 356.48 & 1313.09 \\
$(\mathrm{~J} / \mathrm{kg} . \mathrm{K})$ & 1773 & 2123 & 3003 \\
$T_{\text {melt }}(\mathrm{K})$ & & & \\
\hline
\end{tabular}

FeCrAl alloy is the combination of iron, chromium, and aluminum, where the weight percentage of $\mathrm{Cr}$ and $\mathrm{Al}$ are 21 and 5, respectively. Due to its excellent thermal and mechanical properties, and its compatibility with $\mathrm{UO}_{2}$ fuel, it has been proposed to replace $\mathrm{Zr}$-Alloy as an enhanced accident tolerance cladding in LWRs [12,13]. Meanwhile, SiC has been long suggested as cladding for LWRs because it has excellent thermal properties and irradiation resistance $[2,23,24]$. Another advanced cladding concept is to apply a thin coating at the outer surface of the $\mathrm{Zr}$-alloy cladding. In this 
study, $\mathrm{Nb}_{2} \mathrm{AlC}$ was chosen as the coating material due to its excellent thermal properties and a slightly higher thermal neutron capture cross-section than Zr-alloy's [25]. The thickness of the coating was $50 \mu \mathrm{m}$ to minimize the reduction of the reactivity by the coating.

\section{METHODOLOGY}

\section{APR1400 fuel assembly}

APR1400 has 241 fuel assemblies, a total of 93 control element assemblies and 61 instrumentation assemblies located inside the core. Fuel assemblies are arranged in a way that is almost a right circular cylinder with a diameter of $3.647 \mathrm{~m}$ and an active length of $3.81 \mathrm{~m}$. Each fuel assembly has a total of 236 fuel rods located in a $16 \times 16$ array, together with 4 guide tubes and 1 central instrumentation tube. The operating cycles of APR1400 core are set to 18 months with a discharge burnup reaching up to 60,000 MWD/MTU [26]. Each fuel rod in APR1400 consists of a ceramic cylindrical pellet containing enriched Uranium Dioxide $\left(\mathrm{UO}_{2}\right)$ contained within $\mathrm{Zr}$-alloy cladding. The design configurations of fuel assemblies and fuel rods simulated in this study are shown in Fig. 1 and Table 3, respectively.

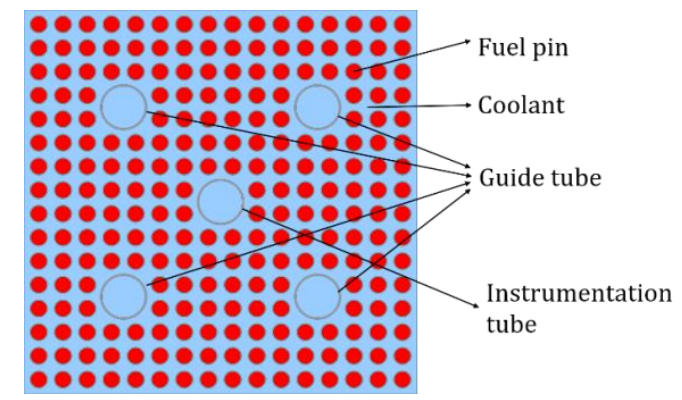

Fig. 1. Fuel assembly model.

Table 3. Fuels assembly and fuel rod design configurations [23]

\begin{tabular}{lc}
\multicolumn{1}{c}{ Parameter } & Value \\
\hline Pellet material & $\mathrm{UO}_{2}$ \\
Pellet diameter $(\mathrm{cm})$ & 0.8192 \\
Pellet density $\left(\mathrm{g} / \mathrm{cm}^{3}\right)$ & 10.340 \\
Pellet enrichment $(\%)$ & 5 \\
Clad material & $\mathrm{Zr}$-alloy \\
Clad inner diam. $(\mathrm{cm})$ & 0.8375 \\
Clad outside diam. $(\mathrm{cm})$ & 0.9520 \\
Clad density $\left(\mathrm{g} / \mathrm{cm}^{3}\right)$ & 6.5220 \\
Guide tube material & $\mathrm{Zr}$-alloy \\
Guide tube inner diam. $(\mathrm{cm})$ & 1.1376 \\
Guide tube outer diam. $(\mathrm{cm})$ & 1.2395 \\
Instrumentation tube inner diam. (cm) & 1.1452 \\
Instrumentation tube outer diam. $(\mathrm{cm})$ & 1.2470 \\
Space grid material & $\mathrm{Zr}$-alloy \\
Space grid linear density $(\mathrm{g} / \mathrm{cm})$ & 2.903 \\
Pin pitch $(\mathrm{cm})$ & 1.2878 \\
Assembly pitch (cm) & 20.8756 \\
Power density (W/gU) & 36.8225 \\
\hline
\end{tabular}

\section{Serpent 2 monte carlo code}

All the required simulations in this study were performed by the Serpent 2 code developed by the VTT Technical Research Center of Finland. It is a continuous-energy Monte Carlo three-dimensional transport code with the capability to perform burnup calculations [10]. Meanwhile, the ENDF/B-VII.1 nuclear data library [27] was used. In this study, each fuel assembly was modeled as a twodimensional problem, and a reflective boundary condition was applied. The number of the neutron histories during the burn-up was 30,000, with the total active cycles of 200 and 50 inactive cycles, providing about $20 \mathrm{pcm}$ standard deviations of multiplication factor $k$. For the reactivity coefficients, the number of neutron histories was increased to 300,000 to reduce the uncertainty of $k$.

\section{Linear reactivity method}

The linear reactivity method is used to find the fuel residence time in a multi-batch core by using the information from the lattice calculation. It is a declaration that the reactivity is a linear function of burn-up as shown in Eq. (1) where $\rho_{o}$ is the reactivity controlled by the poison at the beginning of life $(\Delta k / k), A$ is a constant $(\mathrm{kg} \mathrm{U} / \mathrm{MWd})$ relating to a linear function of fuel conversion ratio and has different values for different fuel enrichment and fuel-to-moderator ratio, and $B$ is burn-up (MWd/kg U) [28].

$$
\rho(B)=\rho_{o}-A B
$$

In the beginning, the fresh fuel that is inserted in the reactor core is controlled at $k=1$ or zero reactivity by inserting enough amount of control absorber. As the burning up carries on, the control absorber is removed slowly. After that, the reactor core reaches the reactivity-limited end-of-cycle (EOC) condition, where $\rho=0$, which means that part of the fuels in the core around $1 / n$ has been burned and will be replaced by new fresh fuel, where $n$ is considered as the number of fuel batches.

For fixed fuel assembly design, the discharge burnup $B_{d}$ and the cycle burnup $B_{c}$ can be calculated as follows. First, the end of burnup $B_{1}$ of fuel assembly is calculated by Eq. (2) when the end of the reactivity-life or $\rho_{\text {end }}$ is 0 . In this work, the $\rho_{\text {end }}$ was assumed to be $3 \%$ to count the neutron leakage difference in the fuel lattice and the core [29]. Then, $B_{c}$ can be calculated by using Eq. (3). Finally, the whole cycle discharge burnup $B_{d}$ is calculated 
by using Eq. (4). Finally, the fuel residence time (years) is calculated by using Eq. (5) where $M(U)$ is the mass of uranium in the fuel assembly $(\mathrm{kg})$, and $P_{\text {assm }}$ is the power of the fuel assembly (MWth).

$$
\begin{gathered}
B_{1}=\frac{\rho_{o}}{A} \\
B_{c}=\frac{2}{n+1} B_{1}=\frac{2}{n+1} \frac{\rho_{o}}{A} \\
B_{d}=n B_{c}=\frac{2 n}{n+1} B_{1}=\frac{2 n}{n+1} \frac{\rho_{o}}{A} \\
t=\frac{B_{d} \times M(U)}{P_{\text {assm }}}
\end{gathered}
$$

\section{RESULTS AND DISCUSSION}

\section{Centerline fuel temperature}

A 1-D single-channel thermal-hydraulics code was created to analyze the radial temperature distribution in the fuel rod, including the centerline fuel temperature [30]. The average bulk coolant temperature, average fuel pin power, and average mass flow rate of APR1400 were used in the script. The heat transfer coefficient for the coolant was calculated by using the Dittus-Boelter correlation. Moreover, the empirical formula for the fuel and clad thermal conductivity was also used [19].

Table 4 compares the centerline fuel temperature for different fuels and claddings, and it shows that the three advanced fuels have a lower centerline temperature compared to the $\mathrm{UO}_{2}$ fuel due to their high thermal conductivities. Moreover, the results also show that $\mathrm{SiC}$ cladding gives the lowest centerline temperature because it also has the highest thermal conductivity and the highest specific heat capacity among the other different advanced claddings.

Table 4. Centerline fuel temperature (K) for different fuel and clad.

\begin{tabular}{lcccc}
\hline \multicolumn{1}{c}{ Cladding } & $\mathbf{U O}_{\mathbf{2}}$ & $\mathbf{U C}$ & $\mathbf{U}_{\mathbf{3}} \mathbf{S i}_{\mathbf{2}}$ & $\mathbf{U N}_{\mathbf{N}} \mathbf{U}_{\mathbf{3}} \mathbf{S i}_{\mathbf{2}}$ \\
\hline Zr-alloy & 1063.91 & 706.29 & 721.75 & 703.18 \\
FeCrAl & 1068.16 & 709.03 & 724.33 & 705.84 \\
Zr-alloy w/ Nb 2 AlC & 1063.91 & 706.29 & 721.75 & 703.18 \\
$\mathrm{SiC}$ & 1038.10 & 689.60 & 706.06 & 687.03 \\
\hline
\end{tabular}

It is worth mentioning that the effective fuel temperature has been used for the lattice calculation. It was calculated using the average function of the temperature profile in the fuel region. The effective temperature was used in Serpent code to get the following results in the subsequent sections and, therefore, to compare the performance of the fuels.

\section{Fuel residence time}

The first neutronics parameter to be compared is the fuel residence time, which is defined as the time between the insertion and removal of a given fuel assembly. The calculated residence time for the three advanced fuels with three different advanced claddings are shown in Table 5, and they are compared to the standard $\mathrm{UO}_{2}$ nuclear fuel. The fuel

\begin{tabular}{|c|c|c|c|c|}
\hline Cladding & $\mathbf{U O}_{2}$ & UC & $\mathbf{U}_{3} \mathbf{S i}_{2}$ & $\mathbf{U N}+\mathbf{U}_{3} \mathbf{S i}_{2}$ \\
\hline Zr-alloy & 4.218 & - & - & - \\
\hline $\mathrm{FeCrAl}$ & 3.325 & 4.698 & 4.105 & 4.720 \\
\hline Zr-alloy w/ $\mathrm{Nb}_{2} \mathrm{AlC}$ & 4.123 & 5.558 & 4.951 & 5.581 \\
\hline $\mathrm{SiC}$ & 4.477 & 5.901 & 5.259 & 5.923 \\
\hline
\end{tabular}
residence time was calculated by using the linear reactivity method and uniform $5 \%$ fuel enrichment.

Table 5. Residence time in years.

It is noticed that the advanced fuels increase the residence time because the fissile density of the advanced fuels is higher than that of $\mathrm{UO}_{2}$ fuel. The advanced cladding also contributes to the fuel residence time depending on its absorption crosssection. FeCrAl, which has the highest thermal neutron capture cross-section among the advanced claddings, as depicted in Fig. 2, reduces the number of thermal neutrons, as illustrated in Fig. 3, and consequently gives a shorter residence time. Meanwhile, the $\mathrm{Zr}$-alloy cladding with $\mathrm{Nb}_{2} \mathrm{AlC}$ coating provides a slight reduction of the fuel residence time compared to the one of $\mathrm{Zr}$-alloy because the thermal neutron capture cross-section of $\mathrm{Nb}_{2} \mathrm{AlC}$ is slightly higher than that of $\mathrm{Zr}$-alloy. Lastly, SiC cladding, which has the lowest thermal neutron capture cross-section and contains neutron moderator carbon, increases the number of thermal neutrons, as shown in Fig. 2, and consequently increases the fuel residence time.

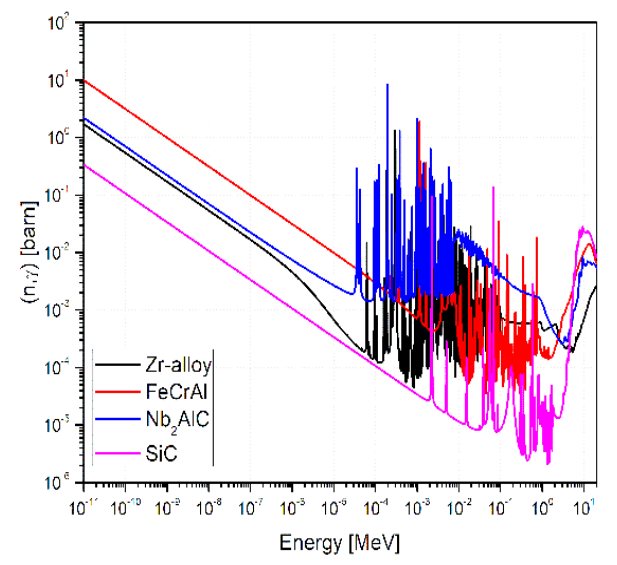

Fig. 2. Microscopic capture cross-sections of claddings. 


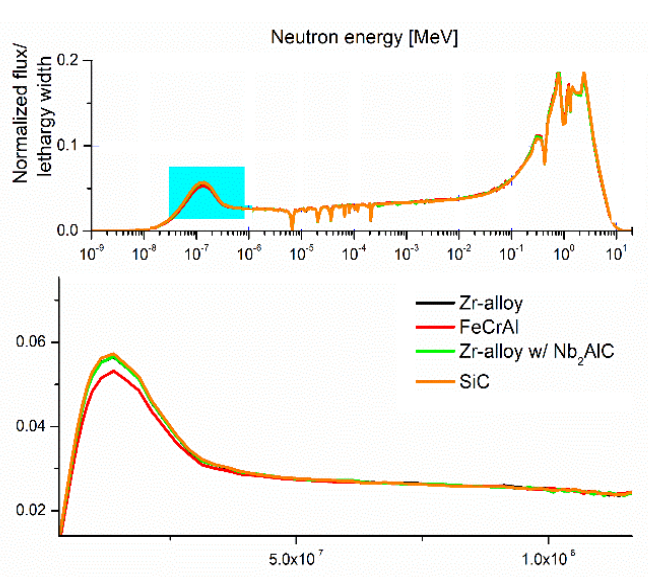

Fig. 3. Neutron spectra for $\mathrm{UO}_{2}$ fuel with different cladding materials.

\section{Reactivity coefficients}

Three primary reactivity coefficients in PWR were calculated in this study. They were Fuel Temperature Reactivity Feedback Coefficient (FTC), Moderator Temperature Reactivity Feedback Coefficient (MTC), and Coolant Void Reactivity Coefficient (CVC).

The FTC was calculated using the Eq. (6) [31] below, in which $k_{1}$ is the multiplication factor at normal fuel operating condition, $k_{2}$ is the multiplication factor at fuel temperature increases by $300 \mathrm{~K}$ from normal fuel operating condition, $T_{1}$ is the fuel temperature at normal fuel operating condition, and $T_{2}$ is the moderator temperature increases by $300 \mathrm{~K}$ from normal fuel operating condition.

$$
F T C=\frac{\frac{1}{k_{2}}-\frac{1}{k_{1}}}{\sqrt{T_{1}}-\sqrt{T_{2}}}
$$

Table 6 summarizes the FTCs at BOC (beginning of cycle) and EOC (end of cycle). The negative FTC values are required as an important inherent safety parameter. It is remarked that FTC values are always negative for any advanced fuel and cladding combinations. At BOC, the FTC values of any advanced fuel and cladding combinations are very close to the FTC value of $\mathrm{UO}_{2}$ and $\mathrm{Zr}$-alloy nuclear fuel system. However, it can be different at EOC depending on the fertile composition in the fuel.

It is well established that the FTC is negative due to the increase of neutron absorption at the resonance energy by the fertile isotopes with the increase of the fuel temperature, which therefore decreases the resonance escape probability and the multiplication factor. It is also observed that at EOC, the FTC value is consistently more negative than that at the BOC due to the build-up of $\mathrm{Pu}-240$, which is also a resonance neutron absorber, from the capture reaction of $\mathrm{Pu}-239$.

Another interesting observation is that $\mathrm{FeCrAl}$ cladding provides more negative FTC than other claddings at BOC due to its large thermal neutron capture cross-section that leads to a smaller number of thermal neutrons in the fuel region. On the other hand, the FTC for FeCrAl cladding is less negative because the discharged burnup of fuel with $\mathrm{FeCrAl}$ cladding is low. Consequently, the amount of $\mathrm{Pu}-240$ is also less compared to other fuel and clad systems.

Table 6. FTC in pcm/K at BOC and EOC.

\begin{tabular}{|c|c|c|c|c|}
\hline Cladding & $\mathbf{U O}_{2}$ & $\mathbf{U C}$ & $\mathbf{U}_{3} \mathbf{S i}_{2}$ & $\mathbf{U N}+\mathbf{U}_{3} \mathbf{S i}_{2}$ \\
\hline \multicolumn{5}{|l|}{ Zr-alloy } \\
\hline $\mathrm{BOC}$ & -104.15 & \multirow{4}{*}{-} & \multirow{4}{*}{-} & \multirow{4}{*}{ - } \\
\hline \multirow{3}{*}{ EOC } & \pm 1.33 & & & \\
\hline & -197.64 & & & \\
\hline & \pm 2.56 & & & \\
\hline \multicolumn{5}{|l|}{$\mathrm{FeCrAl}$} \\
\hline \multirow[t]{2}{*}{ BOC } & -111.57 & -107.15 & $-103.39 \pm$ & $-107.41 \pm$ \\
\hline & \pm 1.66 & \pm 1.41 & 1.24 & 1.32 \\
\hline \multirow[t]{2}{*}{ EOC } & -186.79 & -194.97 & $-185.54 \pm$ & $-187.59 \pm$ \\
\hline & \pm 2.41 & \pm 2.26 & 2.14 & 2.41 \\
\hline \multirow{2}{*}{\multicolumn{5}{|c|}{$\begin{array}{c}\text { Zr-alloy w/ } \\
\mathrm{Nb}_{2} \mathrm{AlC}\end{array}$}} \\
\hline & & & & \\
\hline \multirow[t]{2}{*}{ BOC } & -103.67 & -103.81 & $-95.07 \pm$ & \multirow{4}{*}{$\begin{array}{c}-98.08 \pm 1.30 \\
-203.43 \pm \\
2.42\end{array}$} \\
\hline & \pm 1.46 & \pm 1.25 & 1.22 & \\
\hline \multirow[t]{2}{*}{ EOC } & -195.90 & -202.46 & $-193.79 \pm$ & \\
\hline & \pm 2.52 & \pm 2.28 & 2.35 & \\
\hline \multicolumn{4}{|l|}{$\mathrm{SiC}$} & \multirow{4}{*}{$\begin{array}{c}-99.83 \pm 1.14 \\
-197.61 \pm \\
2.30\end{array}$} \\
\hline \multirow[t]{2}{*}{$\mathrm{BOC}$} & -101.37 & -102.53 & $-93.28 \pm$ & \\
\hline & \pm 1.33 & \pm 1.21 & 1.30 & \\
\hline EOC & $\begin{array}{c}-190.74 \\
\pm 2.37\end{array}$ & $\begin{array}{c}-185.54 \\
\pm 2.14\end{array}$ & $\begin{array}{c}-199.19 \pm \\
2.39\end{array}$ & \\
\hline
\end{tabular}

To determine the MTC, Eq. (7) [31] was used, in which $k_{1}$ is the multiplication factor at normal coolant operating condition, $k_{2}$ is the multiplication factor at coolant temperature increases by $20 \mathrm{~K}, T_{1}$ is the coolant temperature at normal moderator operating condition, and $T_{2}$ is the coolant temperature increases by $20 \mathrm{~K}$ from normal moderator operating condition.

$$
M T C=\frac{\frac{1}{k_{2}}-\frac{1}{k_{1}}}{T_{1}-T_{2}}
$$

From Table 7, it is noticed that the MTC values in BOC and EOC are always negative for any combinations of advanced fuel and cladding. The rise of the coolant temperature reduces the coolant density and consequently reduces the moderating ability and causes an increase in both the resonance escape probability and the neutron leakage. Therefore, the multiplication factor is reduced when the coolant temperature increases. It is shown that the MTC values from the combinations of any advanced fuel and cladding are comparable to 
the one of the current nuclear fuel system, $\mathrm{UO}_{2}$ and Zr-alloy. The MTC values at the EOC, meanwhile, become more negative than at BOC, and they depend on the fuel composition at the discharged condition.

Table 7. $\mathrm{MTC}$ in $\mathrm{pcm} / \mathrm{K}$ at $\mathrm{BOC}$ and $\mathrm{EOC}$.

\begin{tabular}{|c|c|c|c|c|}
\hline Cladding & $\mathbf{U O}_{2}$ & $\mathbf{U C}$ & $\mathbf{U}_{3} \mathbf{S i}_{2}$ & $\mathbf{U N}+\mathbf{U}_{3} \mathbf{S i}_{2}$ \\
\hline \multicolumn{5}{|l|}{ Zr-alloy } \\
\hline $\mathrm{BOC}$ & $\begin{array}{c}-31.46 \pm \\
0.32\end{array}$ & - & - & - \\
\hline EOC & $\begin{array}{c}-70.54 \pm \\
0.59\end{array}$ & & & \\
\hline \multicolumn{5}{|l|}{$\mathrm{FeCrAl}$} \\
\hline $\mathrm{BOC}$ & $\begin{array}{c}-30.93 \pm \\
0.37\end{array}$ & $\begin{array}{c}-35.60 \pm \\
0.38\end{array}$ & $\begin{array}{c}-32.69 \pm \\
0.35\end{array}$ & $\begin{array}{c}-36.26 \pm \\
0.36\end{array}$ \\
\hline $\mathrm{EOC}$ & $\begin{array}{c}-63.94 \pm \\
0.53\end{array}$ & $\begin{array}{c}-72.79 \pm \\
0.62\end{array}$ & $\begin{array}{c}-63.60 \pm \\
0.58\end{array}$ & $\begin{array}{c}-71.82 \pm \\
0.61\end{array}$ \\
\hline \multicolumn{5}{|l|}{$\begin{array}{l}\text { Zr-alloy w/ } \\
\mathrm{Nb}_{2} \mathrm{AlC}\end{array}$} \\
\hline $\mathrm{BOC}$ & $\begin{array}{c}-32.04 \pm \\
0.33\end{array}$ & $\begin{array}{c}-36.51 \pm \\
0.34\end{array}$ & $\begin{array}{c}-33.16 \pm \\
0.32\end{array}$ & $\begin{array}{c}-36.65 \pm \\
0.34\end{array}$ \\
\hline EOC & $\begin{array}{c}-70.24 \pm \\
0.59\end{array}$ & $\begin{array}{c}-81.49 \pm \\
0.60\end{array}$ & $\begin{array}{c}-70.22 \pm \\
0.59\end{array}$ & $\begin{array}{c}-82.13 \pm \\
0.63\end{array}$ \\
\hline \multicolumn{5}{|l|}{$\mathrm{SiC}$} \\
\hline $\mathrm{BOC}$ & $\begin{array}{c}-29.72 \pm \\
0.31\end{array}$ & $\begin{array}{c}-35.00 \pm \\
0.33\end{array}$ & $\begin{array}{c}-30.86 \pm \\
0.35\end{array}$ & $\begin{array}{c}-34.55 \pm \\
0.32\end{array}$ \\
\hline EOC & $\begin{array}{c}-66.16 \pm \\
0.61\end{array}$ & $\begin{array}{c}-80.30 \pm \\
0.64\end{array}$ & $\begin{array}{c}-69.73 \pm \\
0.62\end{array}$ & $\begin{array}{c}-77.39 \pm \\
0.60\end{array}$ \\
\hline
\end{tabular}

Table 8. CVC in pcm/\%void at BOC and EOC.

\begin{tabular}{|c|c|c|c|c|}
\hline Cladding & $\mathbf{U O}_{2}$ & UC & $\mathbf{U}_{3} \mathbf{S i}_{2}$ & $\mathbf{U N}+\mathbf{U}_{3} \mathbf{S i}_{2}$ \\
\hline \multicolumn{5}{|l|}{ Zr-alloy } \\
\hline $\mathrm{BOC}$ & $\begin{array}{c}-383.21 \pm \\
0.11\end{array}$ & - & - & - \\
\hline EOC & $\begin{array}{c}-888.06 \pm \\
0.23\end{array}$ & & & \\
\hline \multicolumn{5}{|l|}{$\mathrm{FeCrAl}$} \\
\hline $\mathrm{BOC}$ & $\begin{array}{c}-370.60 \pm \\
0.11\end{array}$ & $\begin{array}{c}-350.11 \pm \\
0.11\end{array}$ & $\begin{array}{c}-340.04 \pm \\
0.11\end{array}$ & $\begin{array}{c}-348.09 \pm \\
0.11\end{array}$ \\
\hline EOC & $\begin{array}{c}-708.75 \pm \\
0.18\end{array}$ & $\begin{array}{c}-621.89 \pm \\
0.19\end{array}$ & $\begin{array}{c}-616.36 \pm \\
0.16\end{array}$ & $\begin{array}{c}-614.36 \pm \\
0.19\end{array}$ \\
\hline \multicolumn{5}{|l|}{$\begin{array}{c}\text { Zr-alloy w/ } \\
\mathrm{Nb}_{2} \mathrm{AlC}\end{array}$} \\
\hline BOC & $\begin{array}{c}-392.57 \pm \\
0.12\end{array}$ & $\begin{array}{c}-371.07 \pm \\
0.12\end{array}$ & $\begin{array}{c}-360.62 \pm \\
0.12\end{array}$ & $\begin{array}{c}-368.95 \pm \\
0.11\end{array}$ \\
\hline EOC & $\begin{array}{c}-904.07 \pm \\
0.23\end{array}$ & $\begin{array}{c}-752.56 \pm \\
0.20\end{array}$ & $\begin{array}{c}-757.58 \pm \\
0.22\end{array}$ & $\begin{array}{c}-743.61 \pm \\
0.21\end{array}$ \\
\hline \multicolumn{5}{|l|}{$\mathrm{SiC}$} \\
\hline $\mathrm{BOC}$ & $\begin{array}{c}-359.04 \pm \\
0.10\end{array}$ & $\begin{array}{c}-343.23 \pm \\
0.10\end{array}$ & $\begin{array}{c}-331.14 \pm \\
0.10\end{array}$ & $\begin{array}{c}-341.08 \pm \\
0.10\end{array}$ \\
\hline EOC & $\begin{array}{c}-876.01 \pm \\
0.25\end{array}$ & $\begin{array}{c}-712.09 \pm \\
0.19\end{array}$ & $\begin{array}{c}-737.26 \pm \\
0.22\end{array}$ & $\begin{array}{c}-703.52 \pm \\
0.22\end{array}$ \\
\hline
\end{tabular}

Eq. (8) was used to calculate the CVC, where $k_{1}$ is the multiplication factor under normal condition, $k_{2}$ is the multiplication factor under a void percentage of $99 \%$. It is extracted from Table 8 that the CVC values are also negative due to the same reason behind the negative values of MTC. However, the CVC values of advanced fuels are less negative compared to $\mathrm{UO}_{2}$ fuel. The presence of the oxygen in the $\mathrm{UO}_{2}$ fuel, which is about $12 \%$, slightly softens the spectrum when the voiding occurs.

$$
C V C=\frac{\frac{1}{k_{1}}-\frac{1}{k_{2}}}{\text { Void fraction }}
$$

\section{Kinetics parameters}

Two kinetics parameters: effective total delayed neutron fraction $\beta_{\text {eff }}$ and prompt neutron generation time $\Lambda$ were calculated, and they are shown in Tables 9 and 10. These parameters are adjoint-weighted values, calculated by Serpent. It is observed that advanced fuels have a larger $\beta_{\text {eff }}$ and shorter $\Lambda$ at BOC due to higher fissile fraction compared to the $\mathrm{UO}_{2}$ fuel. At EOC, the $\beta_{\text {eff }}$ becomes smaller, and $\Lambda$ becomes slower as the number of $\mathrm{U}-235$ is reduced.

Table 9. $\beta_{\text {eff }}$ in pem at $\mathrm{BOC}$ and $\mathrm{EOC}$.

\begin{tabular}{|c|c|c|c|c|}
\hline Cladding & $\mathbf{U O}_{2}$ & $\mathbf{U C}$ & $\mathbf{U}_{3} \mathbf{S i}_{2}$ & $\mathbf{U N}+\mathbf{U}_{3} \mathbf{S i}_{2}$ \\
\hline \multicolumn{5}{|l|}{ Zr-alloy } \\
\hline $\mathrm{BOC}$ & $\begin{array}{c}676.08 \pm \\
4.58\end{array}$ & - & - & - \\
\hline EOC & $\begin{array}{c}473.88 \pm \\
5.24\end{array}$ & & & \\
\hline \multicolumn{5}{|l|}{$\mathrm{FeCrAl}$} \\
\hline $\mathrm{BOC}$ & $\begin{array}{c}672.54 \pm \\
5.39\end{array}$ & $\begin{array}{c}684.44 \pm \\
5.26\end{array}$ & $\begin{array}{c}681.16 \pm \\
5.02\end{array}$ & $\begin{array}{c}680.71 \pm \\
5.02\end{array}$ \\
\hline EOC & $\begin{array}{c}494.13 \pm \\
5.32\end{array}$ & $\begin{array}{c}481.24 \pm \\
5.22\end{array}$ & $\begin{array}{c}489.43 \pm \\
4.75\end{array}$ & $\begin{array}{c}485.34 \pm \\
5.17\end{array}$ \\
\hline \multicolumn{5}{|l|}{$\begin{array}{l}\text { Zr-alloy w/ } \\
\mathrm{Nb}_{2} \mathrm{AlC}\end{array}$} \\
\hline BOC & $\begin{array}{c}671.29 \pm \\
4.98\end{array}$ & $\begin{array}{c}691.26 \pm \\
4.74\end{array}$ & $\begin{array}{c}681.73 \pm \\
5.09\end{array}$ & $\begin{array}{c}681.97 \pm \\
4.57\end{array}$ \\
\hline EOC & $\begin{array}{c}470.90 \pm \\
5.77\end{array}$ & $\begin{array}{c}473.68 \pm \\
5.19\end{array}$ & $\begin{array}{c}465.11 \pm \\
5.04\end{array}$ & $\begin{array}{c}475.76 \pm \\
5.35\end{array}$ \\
\hline \multicolumn{5}{|l|}{$\mathrm{SiC}$} \\
\hline BOC & $\begin{array}{c}674.29 \pm \\
5.04\end{array}$ & $\begin{array}{c}684.54 \pm \\
4.70\end{array}$ & $\begin{array}{c}683.96 \pm \\
4.86\end{array}$ & $\begin{array}{c}685.76 \pm \\
4.96\end{array}$ \\
\hline EOC & $\begin{array}{c}455.48 \pm \\
5.16\end{array}$ & $\begin{array}{c}474.11 \pm \\
4.94\end{array}$ & $\begin{array}{c}471.43 \pm \\
5.55\end{array}$ & $\begin{array}{c}463.06 \pm \\
5.12\end{array}$ \\
\hline
\end{tabular}

Table 10. $\Lambda$ in $\mu$ s at BOC and EOC.

\begin{tabular}{|c|c|c|c|c|}
\hline Cladding & $\mathbf{U O}_{2}$ & $\mathbf{U C}$ & $\mathbf{U}_{3} \mathbf{S i}_{2}$ & $\mathbf{U N}+\mathbf{U}_{3} \mathbf{S i}_{2}$ \\
\hline \multicolumn{5}{|l|}{ Zr-alloy } \\
\hline \multirow[t]{2}{*}{$\mathrm{BOC}$} & $14.01 \pm$ & \multirow{3}{*}{-} & \multirow{3}{*}{-} & \multirow{3}{*}{-} \\
\hline & 0.01 & & & \\
\hline EOC & $\begin{array}{c}26.59 \pm \\
0.03\end{array}$ & & & \\
\hline \multicolumn{5}{|l|}{$\mathrm{FeCrAl}$} \\
\hline BOC & $\begin{array}{c}13.92 \pm \\
0.01\end{array}$ & $\begin{array}{c}10.90 \pm \\
0.01\end{array}$ & $\begin{array}{c}11.96 \pm \\
0.01\end{array}$ & $\begin{array}{c}10.83 \pm \\
0.01\end{array}$ \\
\hline EOC & $\begin{array}{c}20.00 \pm \\
0.02\end{array}$ & $\begin{array}{c}15.09 \pm \\
0.01\end{array}$ & $\begin{array}{c}17.30 \pm \\
0.02\end{array}$ & $\begin{array}{c}15.07 \pm \\
0.02\end{array}$ \\
\hline \multicolumn{5}{|l|}{$\begin{array}{c}\text { Zr-alloy w/ } \\
\mathrm{Nb}_{2} \mathrm{AlC}\end{array}$} \\
\hline $\mathrm{BOC}$ & $\begin{array}{c}14.11 \pm \\
0.01\end{array}$ & $\begin{array}{c}11.02 \pm \\
0.01\end{array}$ & $\begin{array}{c}12.12 \pm \\
0.01\end{array}$ & $\begin{array}{c}10.99 \pm \\
0.01\end{array}$ \\
\hline EOC & $\begin{array}{c}25.49 \pm \\
0.02\end{array}$ & $\begin{array}{c}17.77 \pm \\
0.02\end{array}$ & $\begin{array}{c}20.96 \pm \\
0.02\end{array}$ & $\begin{array}{c}17.81 \pm \\
0.02\end{array}$ \\
\hline \multicolumn{5}{|l|}{$\mathrm{SiC}$} \\
\hline BOC & $\begin{array}{c}14.07 \pm \\
0.01\end{array}$ & $\begin{array}{c}10.98 \pm \\
0.01\end{array}$ & $\begin{array}{c}12.04 \pm \\
0.01\end{array}$ & $\begin{array}{c}10.92 \pm \\
0.01\end{array}$ \\
\hline EOC & $\begin{array}{c}25.41 \pm \\
0.02\end{array}$ & $\begin{array}{c}17.87 \pm \\
0.02\end{array}$ & $\begin{array}{c}21.77 \pm \\
0.02\end{array}$ & $\begin{array}{c}17.90 \pm \\
0.02\end{array}$ \\
\hline
\end{tabular}




\section{Radial power distribution}

Radial power, which shows the fission power distribution in the radial direction of the lattice, is plotted in Figs. 4 to 11 for a quarter assembly of the current nuclear fuel system ( $\mathrm{UO}_{2}$ and $\mathrm{Zr}$-alloy) and combinations of advanced fuel and cladding at BOC and EOC. The location of the maximum radial power is near the guide tube, where more moderations occur. The maximum radial power is increased by about $2 \%$ at BOC and about $2.8 \%$ at EOC compared to the $\mathrm{UO}_{2}$ and $\mathrm{Zr}$-alloy system when the advanced fuel is used. This increase is expected because the advanced fuels have higher fissile density than $\mathrm{UO}_{2}$. The increment of the radial power does not affect the thermal-hydraulics performance of the reactor since the core operates at critical condition in conjunction with the reactivity control systems. It is also observed that the impact of advanced cladding on the radial power distribution is smaller compared to the advanced fuels.

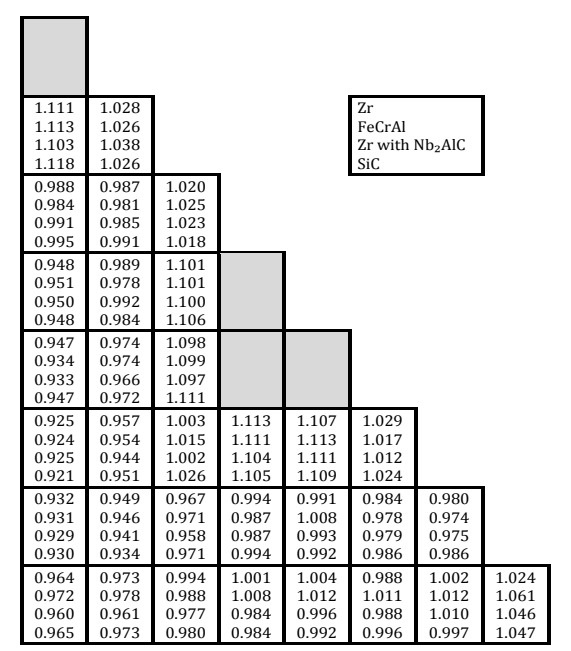

Fig. 4. Normalized radial power distribution for $\mathrm{UO}_{2}$ with different cladding at BOC.

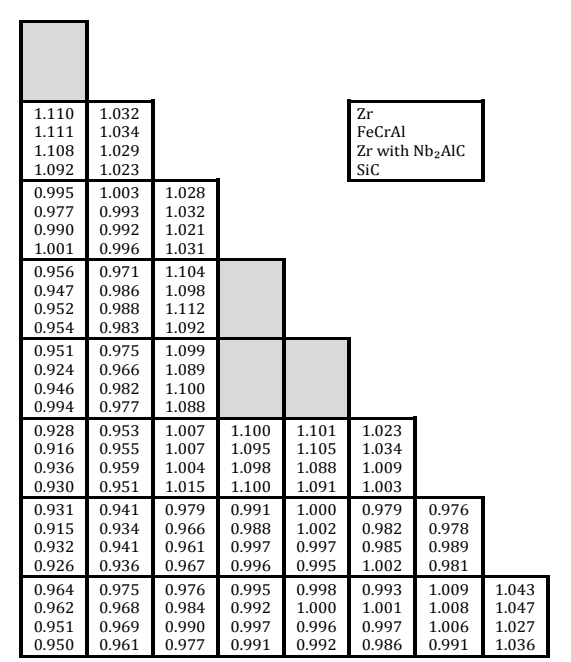

Fig. 5. Normalized radial power distribution for $\mathrm{UO}_{2}$ with different cladding at EOC.

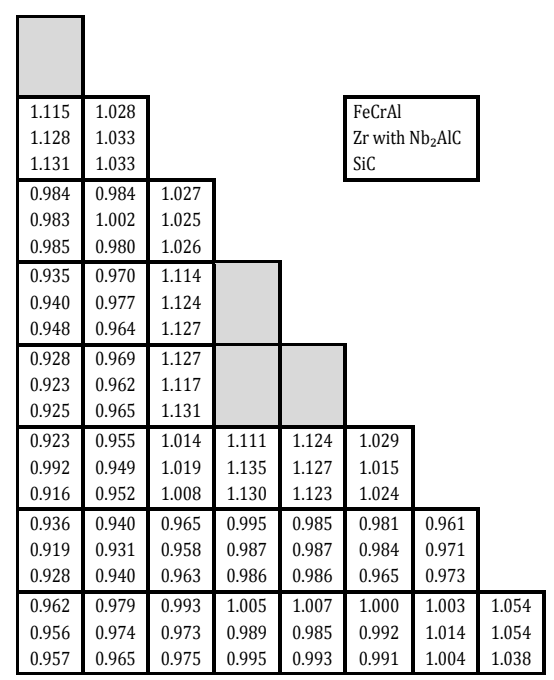

Fig. 6. Normalized radial power distribution for UC with different cladding at BOC.

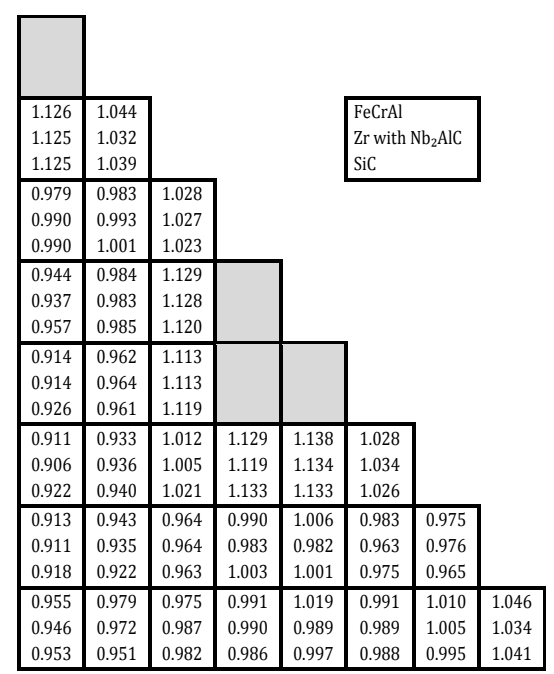

Fig. 7. Normalized radial power distribution for UC with different cladding at EOC.

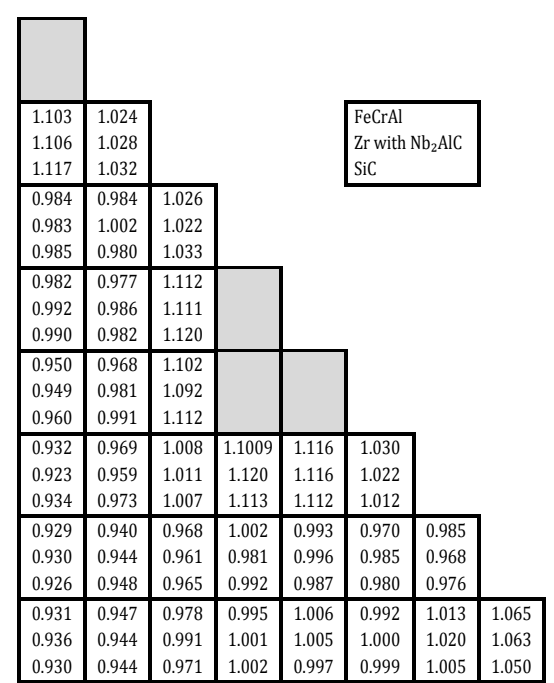

Fig. 8. Normalized radial power distribution for $\mathrm{U}_{3} \mathrm{Si}_{2}$ with different cladding at BOC. 


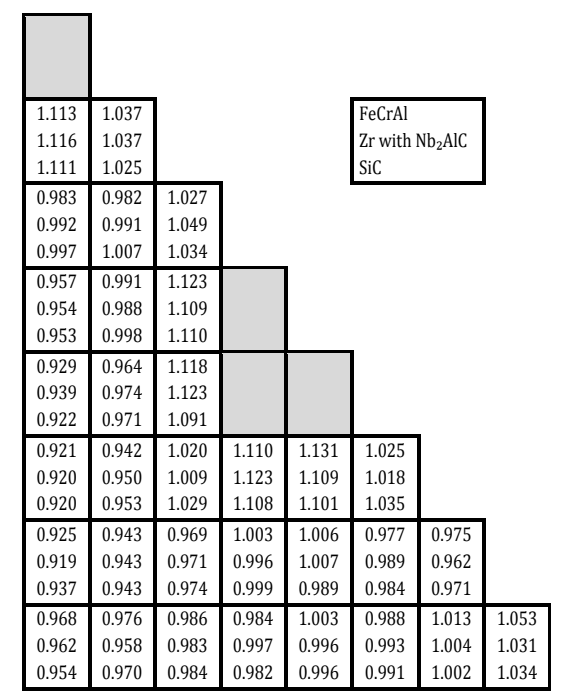

Fig. 9. Normalized radial power distribution for $\mathrm{U}_{3} \mathrm{Si}_{2}$ with different cladding at EOC.

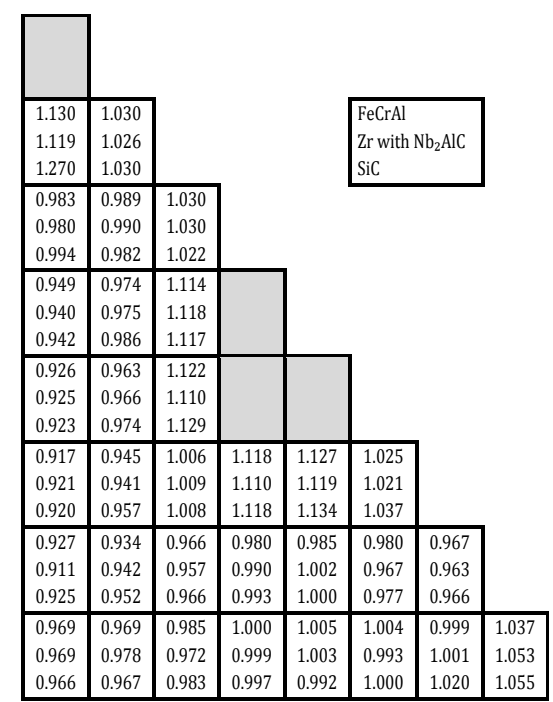

Fig. 10. Normalized radial power distribution for $\mathrm{UN}+\mathrm{U}_{3} \mathrm{Si}_{2}$ with different cladding at BOC.

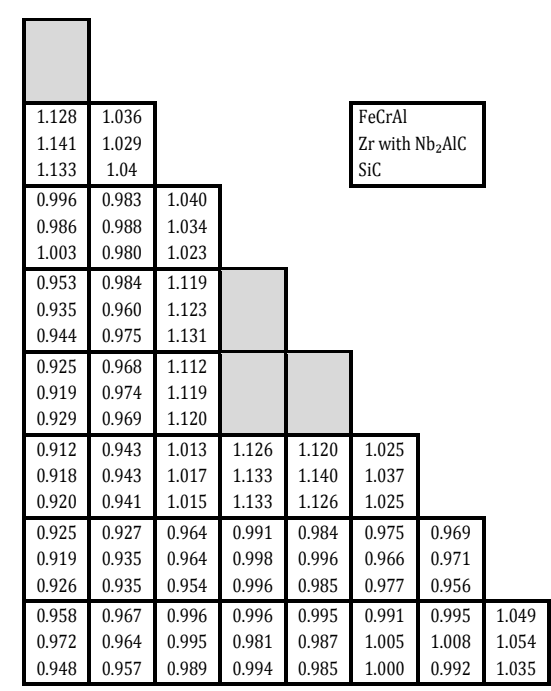

Fig. 11. Normalized radial power distribution for $\mathrm{UN}+\mathrm{U}_{3} \mathrm{Si}_{2}$ with different cladding at EOC.

\section{Fissile isotopes evolution}

Another parameter considered in this study was the build-up of fissile isotope $\mathrm{Pu}-239$ resulting from the neutron capture of U-238. Figure 12 shows that the highest amount of $\mathrm{Pu}-239$ build-up is when $\mathrm{FeCrAl}$ is used as the cladding, and the lowest amount of $\mathrm{Pu}-239$ is given by $\mathrm{SiC}$ cladding. It is also observed from Fig. 13 that more U-238 is consumed when $\mathrm{FeCrAl}$ is used as cladding, and consequently, more $\mathrm{Pu}-239$ is produced. Meanwhile, it is expected that more $\mathrm{Pu}-239$ is consumed when $\mathrm{SiC}$ is used as cladding because of its softer neutron spectrum. Furthermore, the fissile evolution of the advanced fuels shows similar behavior as the standard $\mathrm{UO}_{2}$ fuel for the evolution of U-235, U-238, and Pu-239.

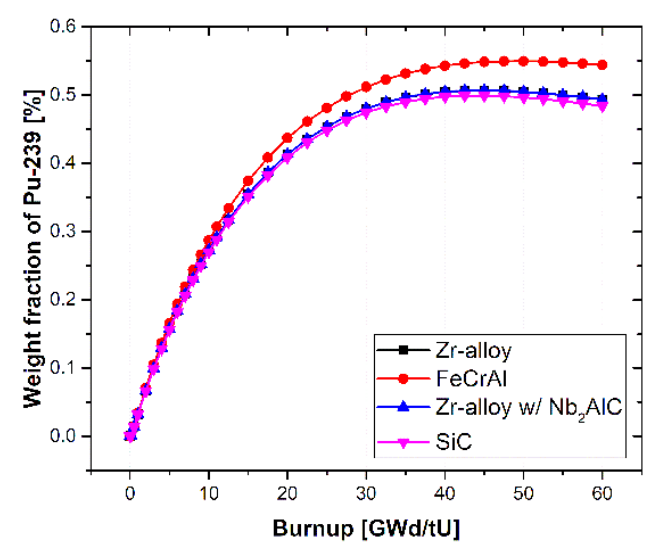

Fig. 12. Evolution of $\mathrm{Pu}-239$ for $\mathrm{UO}_{2}$ fuel with different cladding.

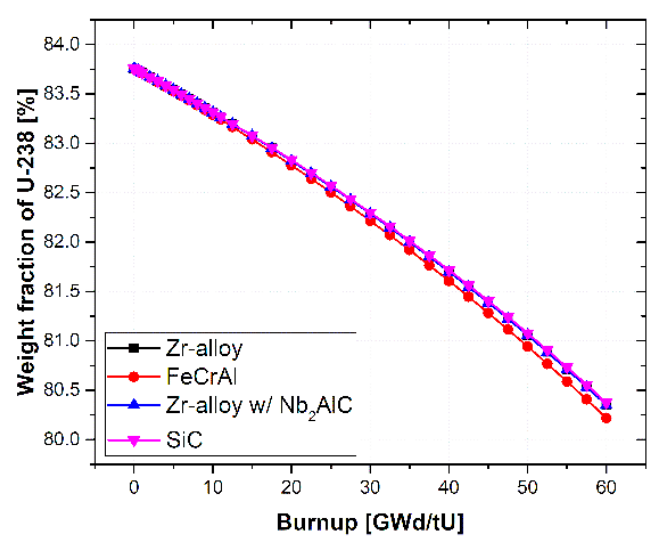

Fig. 13. Evolution of U-238 for $\mathrm{UO}_{2}$ fuel with different cladding.

\section{CONCLUSION}

Three advanced nuclear fuels with three different claddings for the ATF system have been analyzed from the neutronics point of view, and their performance was compared with the current standard nuclear fuel system used in APR1400 $\left(\mathrm{UO}_{2}\right.$ 
and $\mathrm{Zr}$-alloy). The advanced fuels show better performance than current standard nuclear fuel for LWRs. The centerline fuel of the advanced fuels is shown to be much lower because of its excellent thermal properties. In addition, the fuel residence time for the advanced fuels is about 1 year longer than the one of $\mathrm{UO}_{2}$ because advanced fuels have a higher fissile fraction. Furthermore, the reactivity feedback coefficients of the advanced fuels are always negative, and the values at BOC are comparable to the one of $\mathrm{UO}_{2}$ fuel. However, the reactivity feedback values of the advanced fuels can be more negative than the one of $\mathrm{UO}_{2}$ fuel at EOC due to their higher residence time and, consequently, the fuel burnup. Likewise, the kinetics parameters of the advanced fuels at BOC are close to the ones of $\mathrm{UO}_{2}$, and they are slightly smaller at EOC depending on the fissile content at the discharge burnup. It is also interpreted that the radial power distribution of the advanced fuels can be slightly increased compared to $\mathrm{UO}_{2}$ because of higher fissile densities. It can be concluded that if the reactor is using the same level of uranium enrichment as $\mathrm{UO}_{2}$ fuel, the control system worth should be slightly increased for the advanced fuels. Otherwise, a lower enrichment is required for the advanced fuels while maintaining the performance of the current $\mathrm{UO}_{2}$ fuel.

$\mathrm{SiC}$ provides the optimum neutronics performance as cladding compared to other advanced claddings considered in this study due to its lower absorption cross-section and excellent thermal properties. This advanced cladding can be considered as a future cladding in APR1400 while waiting for its readiness. Meanwhile, coating the outer surface of $\mathrm{Zr}$-alloy with, for example, $\mathrm{Nb}_{2} \mathrm{AlC}$ shall be considered since it provides similar performance to the current $\mathrm{Zr}$-alloy cladding with a resistance improvement to the high-temperature steam. However, the use of $\mathrm{FeCrAl}$ as a clad requires slightly higher uranium enrichment to achieve the same performance as the current standard nuclear fuel system due to its high thermal neutron capture cross-section.

\section{REFERENCES}

1. G. Youinou and R.S. Sen, Nucl. Technol. 188 (2014) 123.

2. N.M. George, K. Terrani, J. Powers et al., Ann. Nucl. Energy 75 (2015) 703.

3. B. Cheng, Y. Kim, and P. Chou, Nuclear Engineering and Technology 48 (2016) 16.

4. H.G. Kim, J.H. Yang, W.J. Kim et al., Nuclear Engineering and Technology 48 (2016) 1.
5. S. Younan and D. Novog, Science and Technology of Nuclear Installations 2018 (2018) 17.

6. F. Fejt, M. Sevecek, J. Frybot et al., Ann. Nucl. Energy 124 (2019) 579.

7. S.M. Bragg-Sitton, M. Todosow, R. Montgomery et al., Nuclear Technology 195 (2016) 111.

8. M. Kurata, Nuclear Engineering and Technology 48 (2016) 26.

9. Anonymous, State-of-the-Art Report on Light Water Reactor Accident-Tolerant Fuels, NEA 7317, OECD (2018).

10. Anonymous, ARIS IAEA, https://aris.iaea.org/, Retrieved in May 2019.

11. J. Leppänen, M. Pusa, T. Viitanen et al., Ann. Nucl. Energy 82 (2015) 142.

12. A.T. Nelson, J.T. White, D.D. Byler et al., Transactions of American Nuclear Society 110 (2014).

13. K.A. Gamble, J.D. Hales, G. Pastore et al., Behavior of $\mathrm{U}_{3} \mathrm{Si}_{2}$ Fuel and FeCrAl Cladding under Normal Operating and Accident Reactor Conditions, INL/EXT-16-40059 Rev. 0, Idaho National Laboratory (2016).

14. R. Liu, W. Zhou and J. Cai, Nucl. Eng. Des. 330 (2018) 106.

15. S. Chen and C. Yuan, Science and Technology of Nuclear Installation 2017 (2017) 12.

16. L.H. Ortega, B.J. Blamer, J.A. Evans et al., J. Nucl. Mater. 471 (2016) 116.

17. K.D. Johnson, A.M. Raftery, D.A. Lopes et al., J. Nucl. Mater. 477 (2016) 18.

18. B.J. Prewitt, Analysis and Implementation of Accident Tolerant Nuclear Fuels, MS Thesis, Missouri University of Science and Technology (2017).

19. Anonymous, Thermophysical Properties of Materials for Nuclear Engineering: A Tutorial and Collection of Data, IAEA, Vienna (2009).

20. R. Hidayatullah, D. Hartanto and Y. Kim, Ann. Nucl. Energy 77 (2015) 477.

21. M.A. Fütterer, L. Fu, C. Sink et al., Progress in Nuclear Energy 77 (2014) 266.

22. A. Alemberti, V. Smirnov. C.F. Smith et al., Progress in Nuclear Energy 77 (2014) 300.

23. K.A. Terrani, J. Nucl. Mater. 501 (2018) 13. 
24. Z.X. Tan and J.J. Cai, Nuclear Science and Techniques 30 (2019) 48.

25. I. Younker and M. Fratoni, Progress in Nuclear Energy 88 (2016) 10.

26. Anonymous, APR1400 Design Control Document Tier 2 Chapter 4 Reactor, APR1400K-X-FS-14002-NP, Korea Electric Power Corporation (2014).

27. M.B. Chadwick, M. Herman. P. Obložinský et al., Nuclear Data Sheets 112 (2011) 2887.

28. M.J. Driscoll, T.J. Downar and E.E. Pilat, The Linear Reactivity Model for Nuclear Fuel Management, American Nuclear Society, La
Grange Park (1990).

29. M.S. Yahya, D. Hartanto and Y. Kim, Transactions of American Nuclear Society 113 (2015) 1262.

30. J.J. Duderstadt and L.J. Hamilton, Nuclear Reactor Analysis, John Wiley \& Sons, Inc. (1976).

31. X. Wu, T. Kozlowski, and B.J. Heuser, Neutronics Analysis of Improved Accident Tolerance LWR Fuel by Modifying Zircaloy Cladding of Fuel Pins, International Congress on Advances in Nuclear Power Plants (2014) 159. 